\title{
Analisis sebaran bangunan dan kesesuaian dengan rencana tata ruang wilayah (RTRW) Provinsi DKI Jakarta
}

\author{
Nurwita Mustika Sari ${ }^{(*)}$
}

Prodi S2 Ilmu Geografi, Fakultas MIPA Universitas Gadjah Mada, ${ }^{2}$ Organisasi Riset Penerbangan dan Antariksa (LAPAN), Badan Riset dan Inovasi Nasional

Email Koresponden : nurwita_sutaat@yahoo.com

Direvisi: 2020-11-11 Diterima: 2021-07-07

(C)2021 Fakultas Geografi UGM dan Ikatan Geograf Indonesia (IGI)

\begin{abstract}
Abstrak Pertumbuhan fisik perkotaan dapat ditandai dengan bertambahnya jumlah bangunan yang ada di wilayah tersebut. Bangunan di perkotaan dapat berupa bangunan untuk pemerintahan, perkantoran, permukiman penduduk dan industri. Sebagai lokasi keberadaan ibukota Negara Republik Indonesia, Provinsi DKI Jakarta mengalami pertumbuhan fisik yang sangat pesat. Seiring bertambahnya bangunan di wilayah ini sementara kebutuhan lahan terus meningkat, maka diperlukan pemantauan terhadap sebaran bangunan agar selaras dengan Rencana Tata Ruang Wilayah (RTRW) Provinsi DKI Jakarta. Tujuan penelitian ini adalah melakukan analisis terhadap sebaran bangunan dan kesesuaiannya dengan Rencana Tata Ruang Wilayah (RTRW) Provinsi DKI Jakarta. Metode yang diusulkan dalam penelitian ini adalah analisis Sistem Informasi Geografis (SIG) menggunakan data bangunan eksisting yang diperoleh secara bebas dari Open Street Map (OSM) dan RTRW Jakarta. Hasil analisis SIG kemudian dilanjutkan dengan validasi bangunan yang tidak selaras dengan RTRW menggunakan interpretasi visual data penginderaan jauh SPOT. Hasil menunjukkan bahwa terdapat bangunan seluas 1.016,08 hektar yang tidak selaras dengan RTRW yang seharusnya menjadi kawasan peruntukan fungsi lindung, kawasan peruntukan terbuka hijau budidaya, kawasan peruntukan pertanian dan kawasan peruntukan terbuka non hijau (Ruang Terbuka Biru).
\end{abstract}

Kata kunci: Pertumbuhan fisik perkotaan; Rencana Tata Ruang Wilayah (RTRW), penginderaan jauh; Sistem Informasi Geografis, DKI Jakarta

\begin{abstract}
Urban physical growth can be indicated by the increase of buildings in the area. Buildings in urban areas can be in the form of buildings for government, offices, residential areas and industry. As the location of the capital city of Indonesia, Jakarta Province is experiencing very rapid physical growth. As there are more buildings in this area while the need for land continues to increase, it is necessary to monitor the distribution of buildings so that they are in line with the Regional Spatial Planning (RTRW) of Jakarta Province. The purpose of this study is to analyze the distribution of buildings and their compliance with the Jakarta Regional Spatial Planning (RTRW). The method proposed in this study is a Geographical Information System (GIS) analysis using existing building data which is freely obtained from the Open Street Map (OSM) and Jakarta Regional Spatial Planning. The results of the GIS analysis were then continued with the validation of buildings that were not in line with the Jakarta Regional Spatial Planning using a visual interpretation of the SPOT remote sensing data. The results show that there are buildings with an area of 1,016.08 hectares that are not in line with the Jakarta Regional Spatial Planning, which should be designated as protected areas, open green cultivation areas, agricultural areas and non-green open areas (Blue Open Space).
\end{abstract}

Keywords: urban physical growth; Regional Spatial Planning (RTRW), remote sensing; Geographical Information System, DKI Jakarta

\section{PENDAHULUAN}

Rencana Tata Ruang Wilayah (RTRW) sangat penting bagi suatu daerah untuk menata arah pembangunan wilayah secara fisik agar sesuai dengan fungsi peruntukannya. Perkembangan fisik perkotaan dapat diamati secara multitemporal dengan integrasi metode Sistem Informasi Geografis (SIG) dan penginderaan jauh. Penelitian terkait yang telah dilakukan untuk mengamati perkembangan lahan di enam kota raksasa di China yaitu Beijing, Chongqing, Guangzhou, Shanghai, Shenzhen dan Tianjin yang menunjukkan bahwa telah terjadi perkembangan fisik perkotaan pada keenam kota tersebut selama empat dekade terakhir (Fei \& Zhao, 2019). Penelitian serupa dilakukan untuk melihat bagaimana dinamika penggunaan lahan dan ekspansi lahan terbangun di area metropolitan Hangzhou terjadi selama tiga dekade sejak 1978-2008 menggunakan pendekatan SIG dan penginderaan jauh. Dalam penelitian ini diperoleh hasil bahwa perkembangan lahan di wilayah ini terjadi dengan pola multi inti dan mencapai luas ekspansi lahan terbangun mencapai $542.5 \mathrm{~km}^{2}$ selama tiga dekade (Wu \& Zhang, 2012). Pada wilayah lain yaitu tiga ibukota di Afrika diantaranya Bamako ibukota Mali, Kairo ibukota Mesir dan Nairobi ibukota Kenya terjadi perluasan lahan 
terbangun di ketiga kota ini selama 14 tahun pengamatan. Pertumbuhan lahan terbangun di wilayah Bamako mengurangi luasan area terbuka hijau dan lahan terbuka, sementara untuk wilayah Kairo dan Nairobi pertumbuhan lahan terbangun terjadi sebagian besar di lahan terbuka (Hou et al., 2016). Selain itu telah dikaji pula alih fungsi lahan dari lahan pertanian menjadi lahan terbangun berupa infrastruktur Bandara Internasional Jawa Barat menggunakan teknik penginderaan jauh (Sari \& Kushardono, 2019).

Paradigma pembangunan berkelanjutan mengangkat isu lingkungan sebagai aspek yang harus dijaga dan diselamatkan, maka berbagai upaya dilakukan untuk menekan degradasi lingkungan akibat urbanisasi dan pertumbuhan ekonomi, diantaranya dengan memanfaatkan sumber daya manusia untuk menjalankan urbanisasi yang berkelanjutan serta menerapkan kebijakan yang ditekankan untuk mempertahankan kualitas lingkungan hidup (Ahmed et al., 2020). Implementasi strategi baru dalam menyikapi urbanisasi besar-besaran di China juga diterapkan demi terwujudnya kehidupan warga yang lebih bahagia dan sejahtera serta lingkungan hidup yang tetap lestari. Strategi ini diantaranya adalah penetapan kebijakan terkait lahan dan permukiman perkotaan (Yang et al., 2017). Kebijakan untuk mengatur pembangunan fisik wilayah ini diterapkan di Indonesia salah satunya dengan membuat Rencana Tata Ruang Wilayah (RTRW) yang disusun untuk melaksanakan pembangunan wilayah berkelanjutan dengan cara menerapkan pembangunan fisik wilayah sesuai dengan kawasan peruntukannya.

Sebagai ibukota Negara dan salah satu kota terbesar di Indonesia, bahkan Asia Tenggara, Jakarta mengalami pembangunan wilayah yang sangat pesat baik itu secara fisik maupun sosial ekonomi. Wilayah Provinsi DKI Jakarta merupakan wilayah dengan kawasan peruntukan fungsi ibukota Negara menurut Peraturan Daerah Provinsi DKI Jakarta Nomor 1 Tahun 2012 tentang Rencana Tata Ruang Wilayah Jakarta 2030 (Pemerintah Provinsi DKI Jakarta, 2012). Sebagaimana penelitian di Negara berkembang lain yaitu India, bahwa pertumbuhan wilayah kota-kota di India secara kuat dipengaruhi statusnya sebagai ibukota dan populasi penduduk awal yang dimiliki. Fenomena kota di sekitar kota besar yang ikut berkembang pesat juga terjadi di India (Abhishek et al., 2017). Oleh karena itu penerapan kebijakan untuk mengendalikan dan mengatur pembangunan fisik di perkotaan menjadi tanggung jawab seluruh pemangku kepentingan untuk menghindari terjadinya urban sprawl seperti terjadi di ibukota-ibukota provinsi di China (Lu et al., 2019).

Dalam penelitian lain telah dilaksanakan evaluasi rencana tata ruang berupa pola ruang dan struktur ruang berdasarkan data spasial kebencanaan sehingga diketahui kondisi existing yang terletak di wilayah rawan bencana (Suryanta \& Nahib, 2016). Sementara itu penelitian untuk mengevaluasi tingkat kerawanan bencana seperti banjir dan rob telah dilakukan untuk wilayah lahan terbangun dan permukiman di berbagai wilayah (Ilhami et al., 2014; Kusuma et al., 2013; Putra et al., 2019). Analisis terhadap indeks vegetasi dan teknik SIG untuk menghitung luasan tutupan vegetasi telah dilakukan di Kota Denpasar (As-syakur \& Adnyana, 2009) serta studi terkait kualitas objek tunggal vegetasi yang ada di perkotaan (Sari \& Kushardono, 2016). Dalam penelitian lain, aplikasi penginderaan jauh dan SIG digunakan untuk membuat model ekspansi perkotaan dengan Shannon's Entropy (Prasetyo et al., 2017). Secara khusus terkait objek perkotaan berupa lahan terbangun, penelitian terkait ekstraksi lahan terbangun telah dilakukan dengan indeks dari data penginderaan jauh (Ardiansyah et al., 2019; Hidayati et al., 2018).

Penelitian untuk menganalisis sebaran bangunan yang ada hingga saat ini Provinsi DKI Jakarta penting dilakukan. Dengan dilaksanakannya penelitian ini maka dapat diketahui bagaimana kesesuaian pembangunan fisik perkotaan terhadap RTRW Provinsi DKI Jakarta, apakah mengikuti arahan sesuai dengan kawasan peruntukannya. Hal penting yang menjadi perhatian adalah bahwa ada kawasan-kawasan dengan peruntukan yang secara regulasi tidak boleh dibuat bangunan di atasnya, meliputi kawasan peruntukan fungsi lindung, kawasan peruntukan terbuka hijau budidaya, kawasan peruntukan pertanian dan kawasan peruntukan terbuka non hijau (ruang terbuka biru). Keempat wilayah inilah yang dalam RTRW dirancang sebagai kawasan tanpa bangunan dengan peruntukan fungsi lindung untuk melestarikan lingkungan hidup dan sumber daya alam sebagaimana fungsi hutan rakyat yang harus dijaga eksistensinya (Purbawiyatna et al., 2012), ruang terbuka hijau sebagai kawasan resapan air, penyerap polutan udara, penurun suhu lingkungan, meredam kebisingan juga fungsi lain untuk kegiatan sosial masyarakat (Mukhoriyah et al., 2019), ruang terbuka biru untuk pengendali bencana banjir, penyerap karbon, penyimpanan air, wisata, pembangkit listrik (Arifin, 2014), dan kawasan peruntukan pertanian untuk pemanfaatan oleh masyarakat untuk mendukung ketahanan pangan dan mempertahankan lahan pertanian secara berkelanjutan sehingga lahan pertanian tidak mengalami alih fungsi lahan sebagai dampak urban sprawl (Christiawan, 2019). Analisis sebaran bangunan dan kesesuaiannya dengan RTRW juga menjadi salah satu upaya untuk mendukung terwujudnya tata ruang wilayah Jakarta yang berkelanjutan.

Dalam penelitian ini diharapkan dapat dihasilkan informasi mengenai sebaran bangunan yang tidak sesuai letak atau posisinya dengan RTRW sehingga dengan informasi ini diharapkan dapat menjadi masukan bagi pemangku kepentingan untuk dapat mengendalikan pendirian bangunan agar selaras dengan RTRW sehingga fungsi masing-masing kawasan dapat terwujud dengan baik dan berbagai permasalahan yang timbul dari pembangunan fisik suatu wilayah yang tidak teratur dapat dihindari, misalnya terjadinya bencana alam.

\section{METODE PENELITIAN}

Data utama yang digunakan dalam penelitian ini adalah data vektor rencana pola ruang daratan Provinsi DKI Jakarta Tahun 2030 yang merupakan bagian dari Rencana Tata Ruang Wilayah (RTRW) Provinsi DKI Jakarta sebagaimana diatur dalam Peraturan Daerah Provinsi DKI Jakarta Nomor 1 Tahun 2012 tentang Tata Ruang Wilayah Jakarta 2030. Data ini bersumber dari Dinas Cipta Karya, Tata Ruang dan Pertanahan Provinsi DKI Jakarta.

Data kedua adalah data vektor rencana pola ruang wilayah kajian disajikan pada Gambar 2. Data lain yang digunakan adalah data bangunan yang existing di wilayah Provinsi DKI Jakarta. Data ini bersumber dari OSM (Open Street Map), yang merupakan sumber data spasial yang dapat diakses secara bebas dan gratis yang dibuat komunitas kontributor bidang pemetaan untuk memetakan berbagai data, salah satunya yaitu bangunan. 
Data selanjutnya yang digunakan dalam penelitian ini adalah data penginderaan jauh resolusi tinggi SPOT 6/7 yang merupakan data citra mosaik citra SPOT untuk periode akuisisi tahun 2017 hingga 2018 bebas awan di wilayah kajian. Data citra satelit resolusi tinggi ini berasal dari Lembaga Penerbangan dan Antariksa Nasional (LAPAN). Peta citra satelit dari data SPOT 6/7 ditampilkan pada Gambar 3.

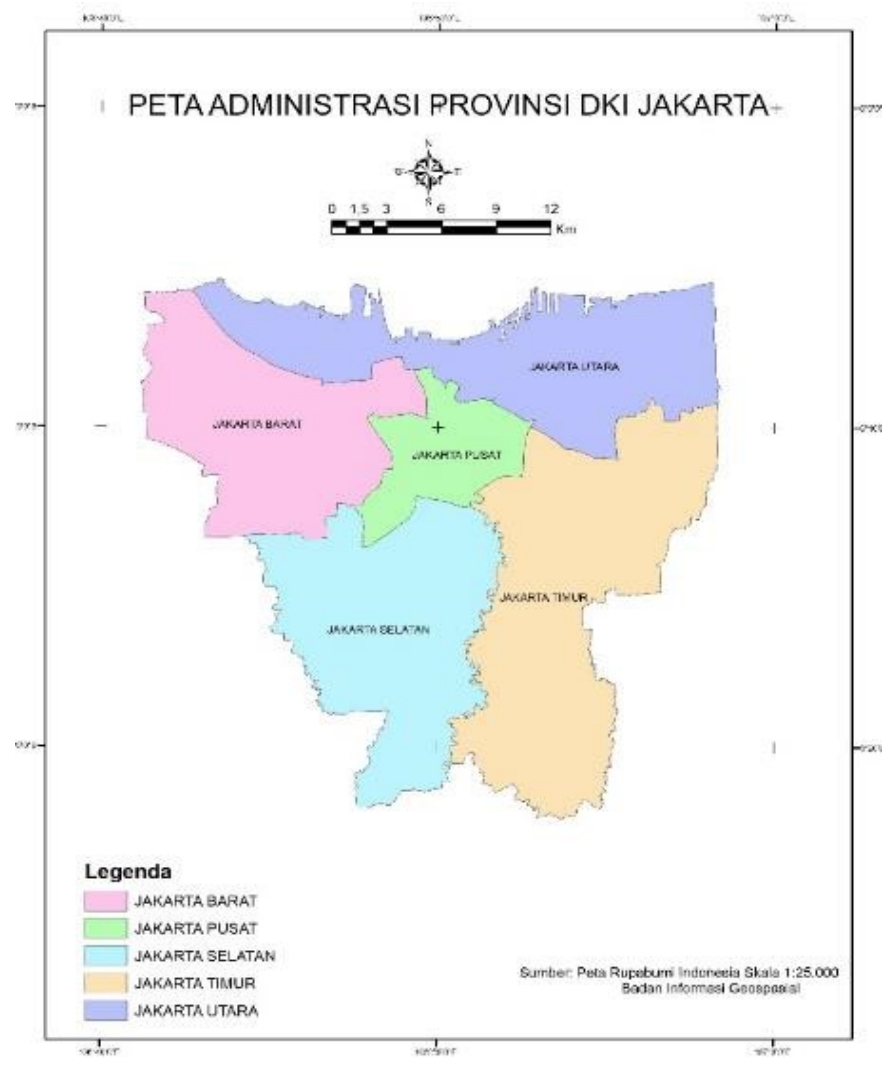

Gambar 1. Wilayah kajian

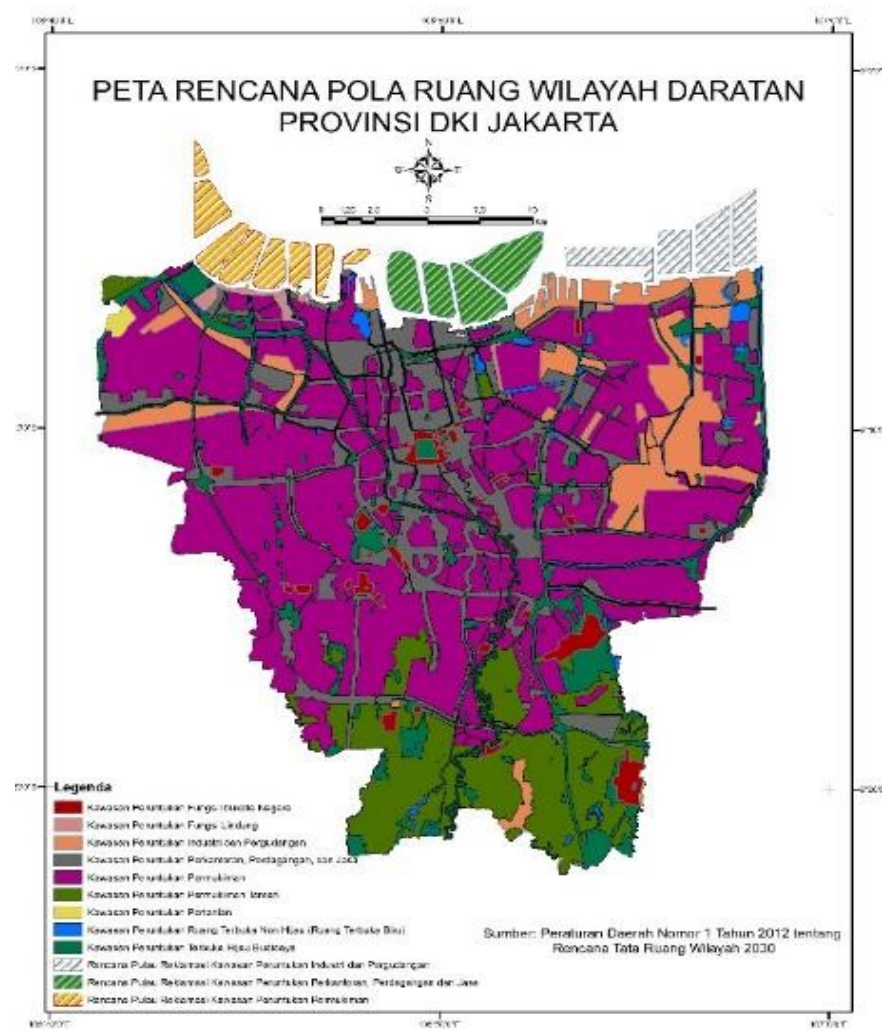

Gambar 2. Peta rencana pola ruang wilayah kajian

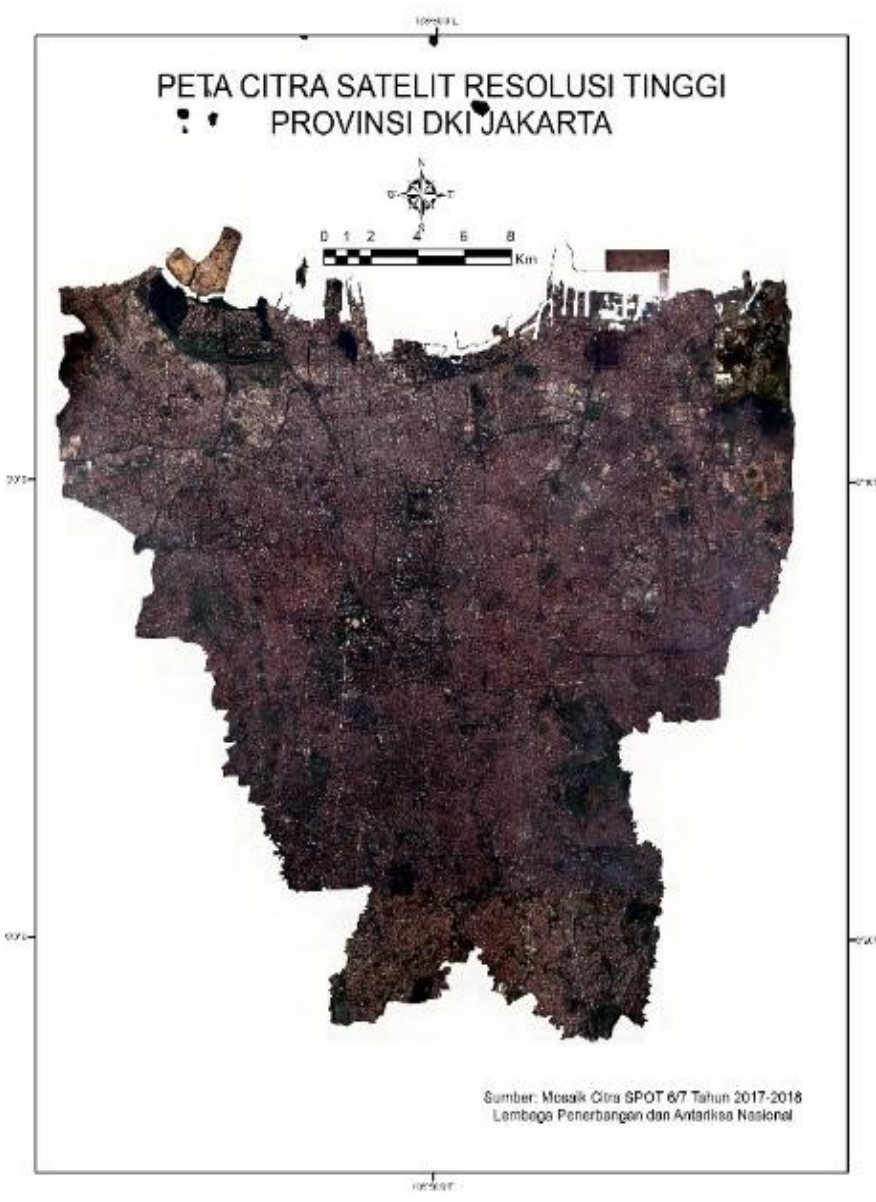

Gambar 3. Peta citra satelit resolusi tinggi wilayah kajian

Wilayah kajian yaitu Provinsi DKI Jakarta bagian daratan yang meliputi kota Jakarta Pusat, Jakarta Utara, Jakarta Barat, Jakarta Timur dan Jakarta Selatan.

Tahapan penelitian dapat dilihat pada Gambar 4. Pada tahap awal penelitian dilakukan persiapan bahan yang dibutuhkan dalam penelitian yaitu data vektor rencana pola ruang Provinsi DKI Jakarta tahun 2030 yang merupakan bagian dari Rencana Tata Ruang Wilayah Provinsi DKI Jakarta 2030, data vektor bangunan existing di Provinsi DKI Jakarta dan data citra SPOT 6/7 Provinsi DKI Jakarta. Dari data vektor rencana pola ruang, selanjutnya diekstraksi sehingga menjadi empat kawasan.

Tahapan selanjutnya yaitu analisis SIG mengggunakan data bangunan dan data empat kawasan sehingga diperoleh data bangunan yang tidak selaras dengan RTRW atau not comply. Dari hasil berupa data yang tidak selaras ini kemudian dilakukan validasi dengan teknik interpretasi visual dengan citra SPOT 6/7 untuk menguji akurasi hasil analisis SIG berupa bangunan yang tidak selaras dengan tutupan lahan sebenarnya.

Uji akurasi dilakukan dengan confusion matrix untuk hasil kelas biner. Uji akurasi dilakukan dengan memilih 40 sampel secara acak pada seluruh lokasi penelitian dengan bangunan yang tidak selaras. Selanjutnya pada 40 sampel ini masing-masing dicek kondisi tutupan lahannya dari citra SPOT 6/7 kemudian dimasukkan ke kategori yaitu TP (True Positive), FP (False Positive), TN (True Negative) dan FN (False Negative). 
Tabel 1. Kategori kesesuaian bangunan existing dengan RTRW

\begin{tabular}{llc}
\hline Fungsi sesuai RTRW & $\begin{array}{l}\text { Keberadaan bangunan (dari data } \\
\text { OSM) }\end{array}$ & Kategori \\
\hline Kawasan peruntukan fungsi lindung & $\begin{array}{l}\text { Ada di dalam poligon kawasan } \\
\text { fungsi lindung } \\
\text { Ada di dalam poligon RTH budidaya }\end{array}$ & Tidak sesuai \\
Kawasan peruntukan terbuka hijau budidaya & Ada dalam kawasan pertanian & Tidak sesuai \\
$\begin{array}{l}\text { Kawasan peruntukan pertanian } \\
\begin{array}{l}\text { Kawasan peruntukan ruang terbuka non hijau } \\
\text { (ruang terbuka biru) }\end{array}\end{array}$ & Ada dalam kawasan RTB & Tidak sesuai \\
\hline
\end{tabular}
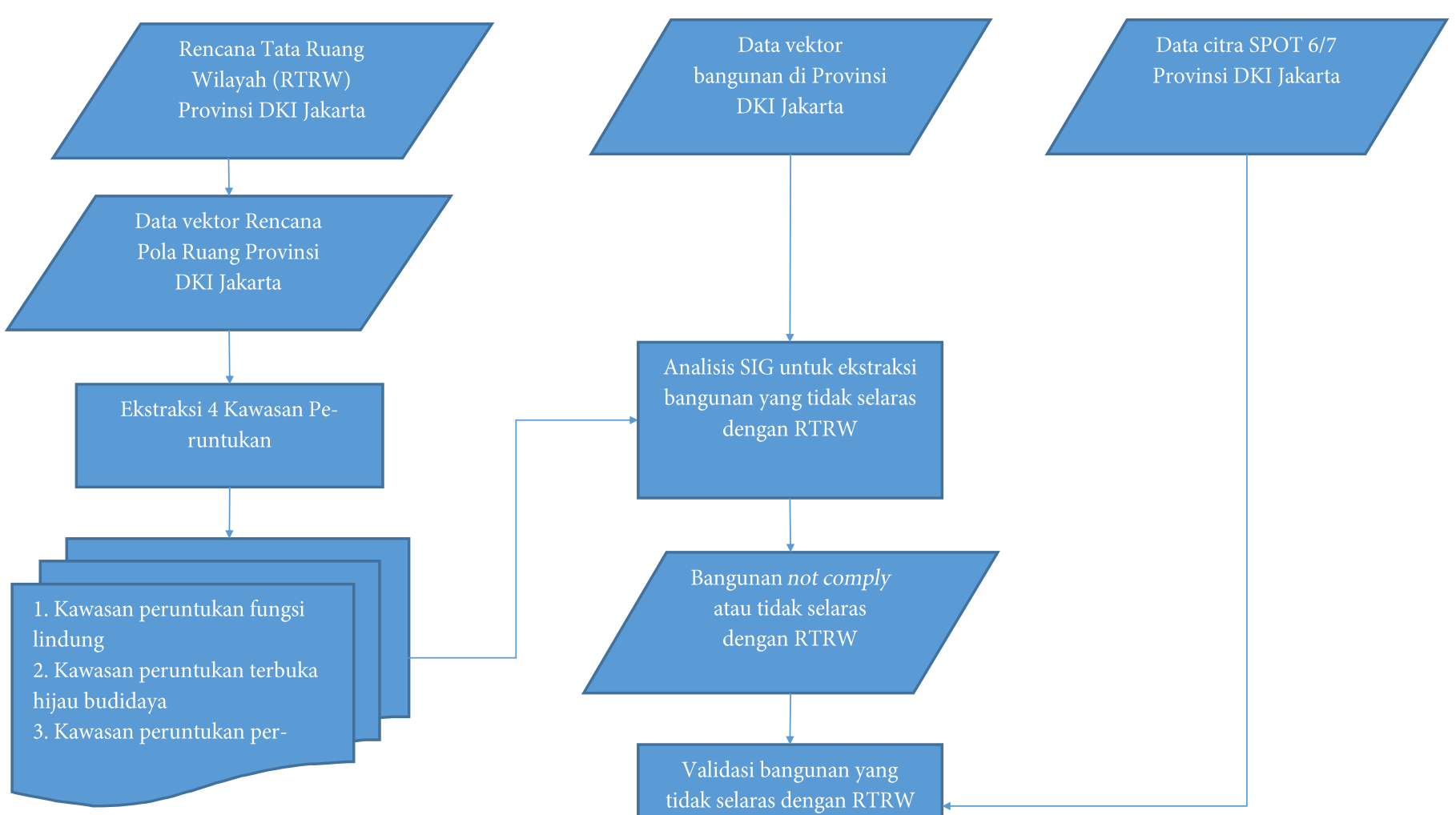

Analisis hasil

Gambar 4. Diagram alir analisis sebaran bangunan dan kesesuaian dengan RTRW Provinsi DKI Jakarta

Tabel 2. Confusion Matrix

Nilai Prediksi
1 (Positif)
0 (Negatif)

\begin{tabular}{cc} 
& Nilai Aktual \\
& 1 (Positif) dan 0 (Negatif) \\
\hline TP & FP \\
TN & FN
\end{tabular}

\section{HASIL DAN PEMBAHASAN}

Hasil pertama yaitu hasil ekstraksi terhadap empat kawasan yang sesuai dengan arahan dalam RTRW memiliki fungsi khusus, dimana di empat kawassan ini tidak bisa dibangun permukiman atau gedung di atasnya. Hasil ditunjukkan oleh Gambar 5. Dari gambar terlihat lokasi kawasan peruntukan fungsi lindung berwarna ungu, kawasan peruntukan terbuka hijau budidaya berwarna biru, kawasan peruntukan pertanian berwarna hijau muda dan kawasan peruntukan ruang terbuka non hijau (ruang terbuka biru) berwarna hijau tua.

Berdasarkan poligon rencana pola ruang dari RTRW, kawasan peruntukan ruang terbuka non hijau (ruang terbuka biru) memiliki luas area 1.634 hektar, kawasan peruntukan terbuka hijau budidaya memiliki luas 7.641, 05 hektar, kawasan peruntukan fungsi lindung seluas 194,01 hektar dan 
kawasan pertanian seluas 167,23 hektar. Hasil kedua adalah peta

bangunan existing dari OSM yang ditunjukkan Gambar 6. Dari hasil plot bangunan terlihat bahwa distribusi bangunan di wilayah kajian hampir merata di seluruh area dengan kepadatan sangat tinggi. Dari Gambar 6 terlihat bahwa poligon bangunan berwarna merah muda dengan garis tepi abu-abu, yang terlihat sangat padat di seluruh wilayah kajian dan menyisakan sedikit ruang untuk tutupan lahan lain.

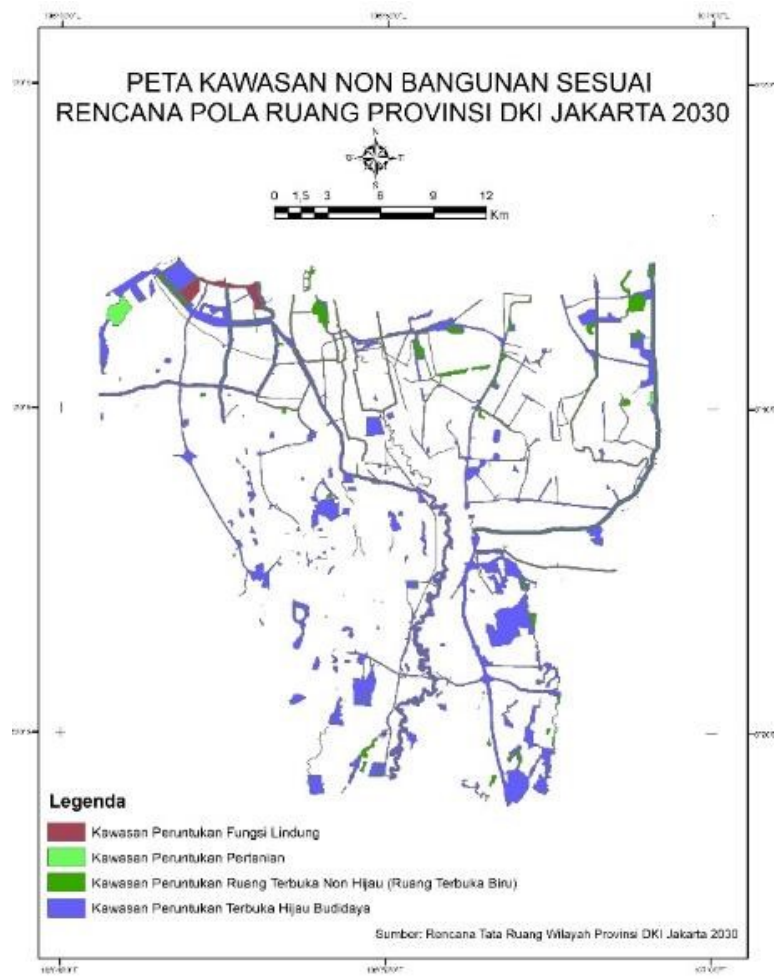

Gambar 5. Peta kawasan non bangunan sesuai rencana pola ruang Provinsi DKI Jakarta 2030

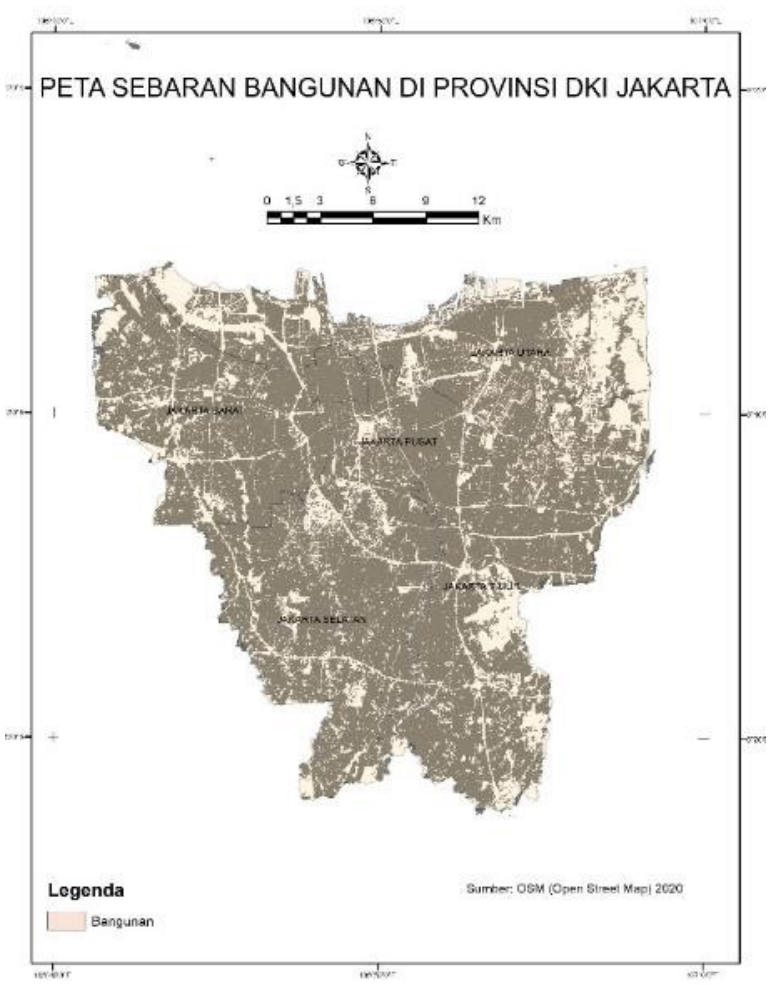

Gambar 6. Peta sebaran bangunan di Provinsi DKI Jakarta
Berdasarkan Gambar 7 dapat dilihat distribusi spasial sebaran bangunan yang tidak selaras dengan rencana pola ruang dalam RTRW Provinsi DKI Jakarta tahun 2030. Oleh karena bangunan yang ditampilkan termasuk dengan permukiman atau hunian serta gedung lainnya dan berukuran cukup kecil untuk ditampilkan pada peta maka sebaran yang terlihat hanya berupa titik atau kumpulan titik. Sebaran bangunan yang tidak selaras atau dapat disebut not comply ini menyebar secara acak namun konsisten di sekitar empat kawasan dengan fungsi khusus sebagaimana telah dijelaskan pada bagian sebelumnya.

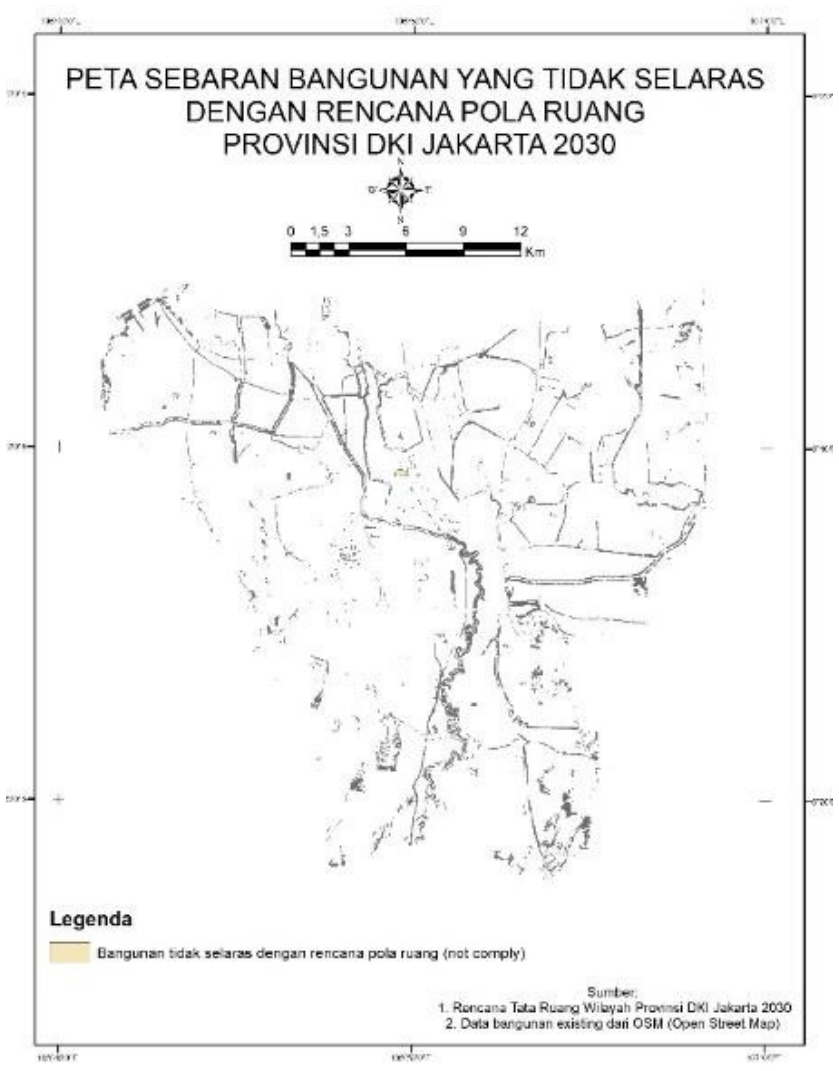

Gambar 7. Peta sebaran bangunan yang tidak selaras dengan rencana pola ruang

Tabel 2. Luas kawasan peruntukan khusus dan luas bangunan yang tidak selaras

\begin{tabular}{llll}
\hline & & \multicolumn{3}{c}{ Luas } \\
bangunan & \\
& Luas & yang tidak & \\
Kawasan Peruntukan & sesuai & Persen- \\
& RTRW & selaras & tase (\%) \\
& (hektar) & dengan & \\
& RTRW & \\
& & (hektar) & \\
\hline
\end{tabular}

Kawasan Peruntukan

Ruang Terbuka Non

Hijau (Ruang Terbuka

Biru)

$1634,00 \quad 83,55$

Kawasan Peruntukan

Terbuka Hijau Budi-

Kawasan Peruntukan

Fungsi Lindung 194,01

$7641,05 \quad 919,76$

12,04

Kawasan Peruntukan

Pertanian

167,23 
Luas kawasan peruntukan khusus sesuai RTRW sebagaimana ditunjukkan oleh Tabel 2 menunjukkan bahwa pada keempat kawasan peruntukan khusus tersebut terdapat bangunan yang tidak selaras dengan RTRW, masing-masing pada kawasan peruntukan ruang terbuka non hijau atau ruang terbuka biru terdapat 83,55 hektar bangunan yang tidak selaras atau sebesar $5,11 \%$ dari total luas kawasan peruntukan RTB sesuai RTRW, selanjutnya untuk kawasan peruntukan terbuka hijau budidaya terdapat 919,76 hektar luas bangunan yang tidak selaras dengan RTRW atau 12,04\% dari total luas kawasan RTH budidaya sesuai RTRW, kemudian untuk kawasan peruntukan fungsi lindung terdapat 5,92 hektar bangunan yang tidak selaras atau sebesar 3,05\% dari total luas kawasan fungsi lindung sesuai RTRW, dan terakhir untuk kawasan peruntukan pertanian terdapat 6,85 hektar bangunan yang tidak selaras. Jadi, total luasan bangunan yang tidak selaras dengan RTRW yaitu 1.016,08 hektar. Dari hasil analisis dapat diketahui bahwa kawasan dengan fungsi peruntukan terbuka hijau budidaya merupakan kawasan yang paling banyak memiliki bangunan tidak selaras dengan RTRW.

Uji akurasi untuk validasi data bangunan yang tidak selaras dengan RTRW dilakukan dengan sebaran sampel sebagaimana Gambar 8. Sampel yang dipilih sejumlah 40 yang tersebar di seluruh wilayah kajian. Dari peta sebaran sampel dapat dilihat lokasi sampel adalah yang berwarna kuning sementara itu bangunan not comply atau tidak selaras RTRW berwarna merah.

Beberapa lokasi sampel yang diperbesar untuk uji akurasi ditampilkan pada Gambar 9. Poligon berwarna merah merupakan bangunan yang tidak selaras dengan RTRW, poligon berwarna biru adalah kawasan peruntukan terbuka hijau budidaya sesuai RTRW dan poligon berwarna hijau adalah kawasan peruntukan ruang terbuka non hijau (ruang terbuka biru).

Hasil uji akurasi disajikan dalam Tabel 3, dimana ada 40 sampel uji akurasi dalam penelitian ini. Pada setiap nomor sampel terdapat keterangan yang menunjukkan hasil pengecekan model (prediksi) dengan kondisi sebenarnya (aktual). Sebagian besar sampel memiliki keterangan TP (True Positive) yang terjadi ketika model (prediksi) bernilai 1 dan kondisi sebenarnya (aktual) bernilai 1 atau bangunan

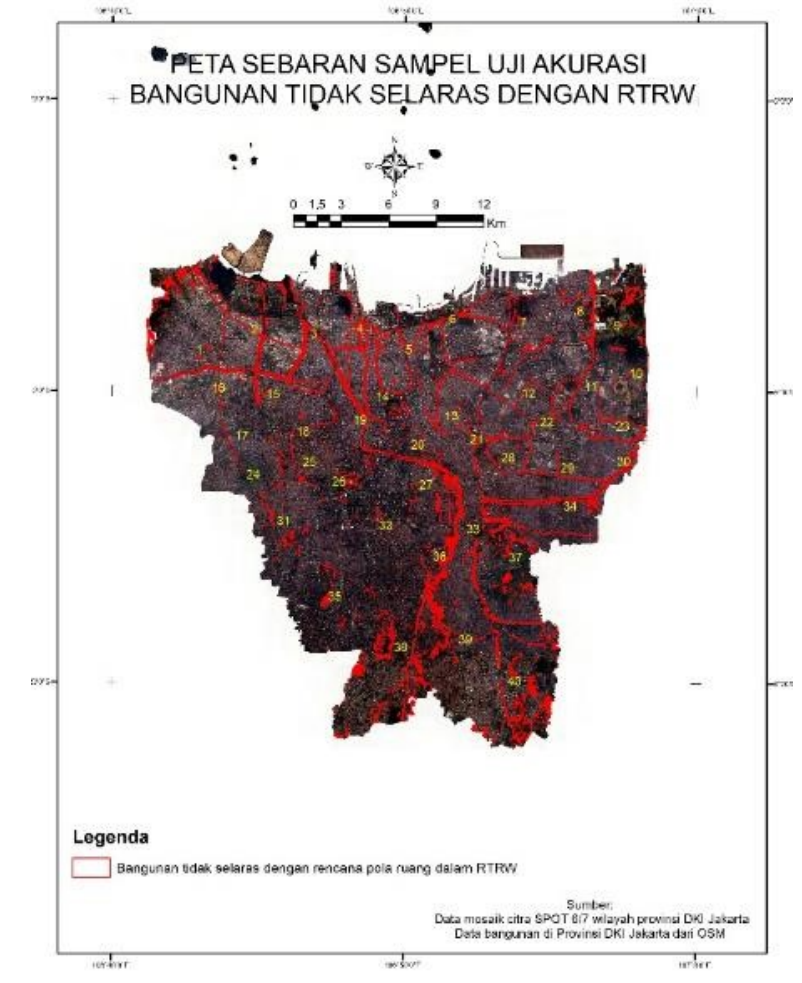

Gambar 8. Peta sebaran sampel uji akurasi

yang diidentifikasi sebagai bangunan tidak selaras dengan RTRW ternyata dalam kondisi aktual memang merupakan lahan terbangun sesuai data referensi yaitu mosaik citra SPOT 6/7. Selanjutnya keterangan FP atau False Positive yaitu ketika prediksi bernilai 1 dan aktual bernilai 0 yang artinya adalah bangunan yang diidentifikasi sebagai bangunan tidak selaras dengan RTRW ternyata kondisi aktual merupakan area yang sesuai dengan RTRW. Kasus ini terjadi pada beberapa lokasi sampel diantaranya nomor 5, 6, 14, 23, 25 dan 32. Keterangan selanjutnya adalah FN yang terjadi ketika prediksi bernilai 0 sedangkan aktual bernilai 1 artinya bahwa di kondisi aktual sudah ada bangunan yang tidak selaras dengan RTRW namun di model (prediksi) tidak ada bangunan. Kasus ini terjadi pada 1 sampel yaitu nomor 26 .

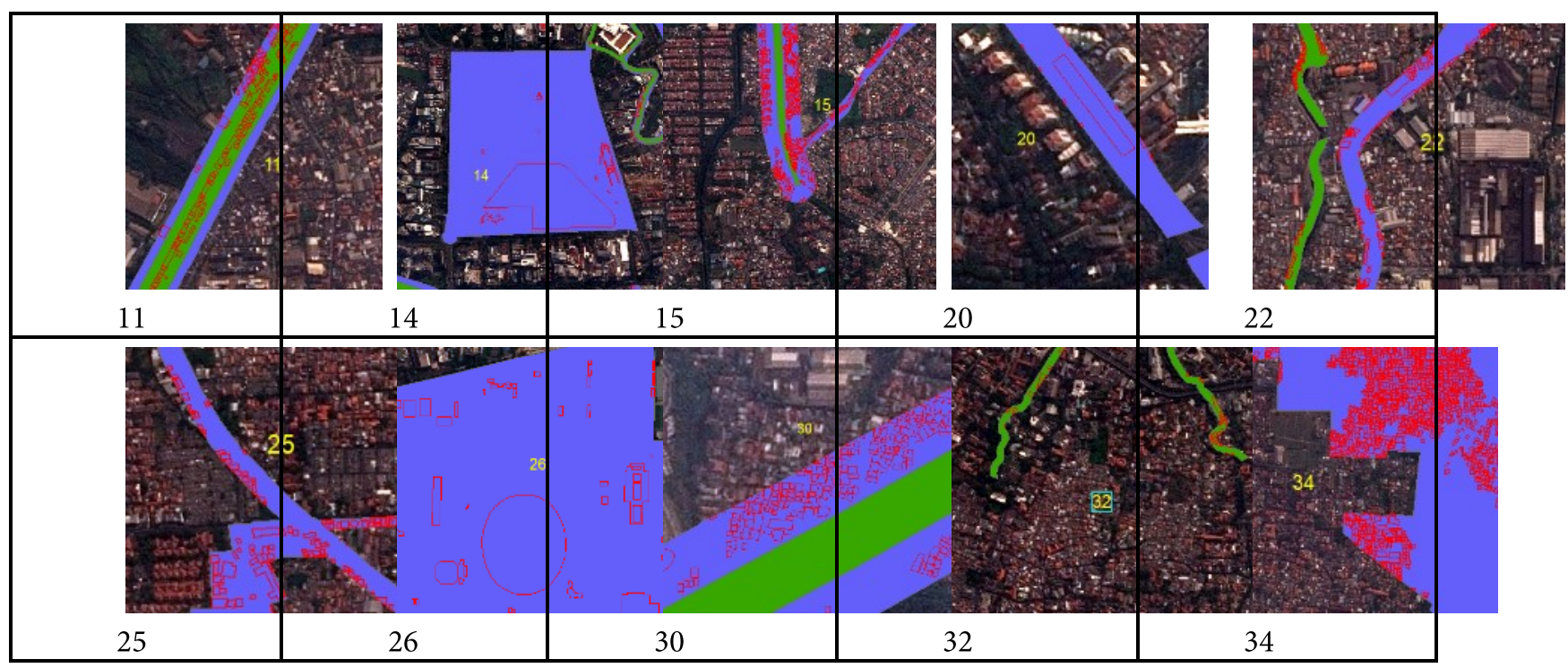

Gambar 9. Beberapa lokasi sampel uji akurasi 
Tabel 3. Uji akurasi hasil analisis sebaran bangunan yang tidak selaras dengan RTRW

\begin{tabular}{|c|c|c|c|}
\hline Nomor sampel & Prediksi & Aktual & Keterangan \\
\hline 1 & 1 & 1 & $\mathrm{TP}$ \\
\hline 2 & 1 & 1 & $\mathrm{TP}$ \\
\hline 3 & 1 & 1 & $\mathrm{TP}$ \\
\hline 4 & 1 & 1 & $\mathrm{TP}$ \\
\hline 5 & 1 & 0 & $\mathrm{FP}$ \\
\hline 6 & 1 & 0 & $\mathrm{FP}$ \\
\hline 7 & 1 & 1 & $\mathrm{TP}$ \\
\hline 8 & 1 & 1 & $\mathrm{TP}$ \\
\hline 9 & 1 & 1 & $\mathrm{TP}$ \\
\hline 10 & 1 & 1 & $\mathrm{TP}$ \\
\hline 11 & 1 & 1 & $\mathrm{TP}$ \\
\hline 12 & 1 & 1 & $\mathrm{TP}$ \\
\hline 13 & 1 & 1 & $\mathrm{TP}$ \\
\hline 14 & 1 & 0 & $\mathrm{FP}$ \\
\hline 15 & 1 & 1 & $\mathrm{TP}$ \\
\hline 16 & 1 & 1 & $\mathrm{TP}$ \\
\hline 17 & 1 & 1 & $\mathrm{TP}$ \\
\hline 18 & 1 & 1 & $\mathrm{TP}$ \\
\hline 19 & 1 & 1 & $\mathrm{TP}$ \\
\hline 20 & 1 & 1 & $\mathrm{TP}$ \\
\hline 21 & 1 & 1 & $\mathrm{TP}$ \\
\hline 22 & 1 & 1 & $\mathrm{TP}$ \\
\hline 23 & 1 & 0 & $\mathrm{FP}$ \\
\hline 24 & 1 & 1 & $\mathrm{TP}$ \\
\hline 25 & 1 & 0 & $\mathrm{FP}$ \\
\hline 26 & 0 & 1 & FN \\
\hline 27 & 1 & 1 & $\mathrm{TP}$ \\
\hline 28 & 1 & 1 & $\mathrm{TP}$ \\
\hline 29 & 1 & 1 & $\mathrm{TP}$ \\
\hline 30 & 1 & 1 & $\mathrm{TP}$ \\
\hline 31 & 1 & 1 & $\mathrm{TP}$ \\
\hline 32 & 1 & 0 & $\mathrm{FP}$ \\
\hline 33 & 1 & 1 & $\mathrm{TP}$ \\
\hline 34 & 1 & 1 & $\mathrm{TP}$ \\
\hline 35 & 1 & 1 & $\mathrm{TP}$ \\
\hline 36 & 1 & 1 & $\mathrm{TP}$ \\
\hline 37 & 1 & 1 & $\mathrm{TP}$ \\
\hline 38 & 1 & 1 & $\mathrm{TP}$ \\
\hline 39 & 1 & 1 & $\mathrm{TP}$ \\
\hline 40 & 1 & 1 & $\mathrm{TP}$ \\
\hline Total & 39 & 34 & \\
\hline \multicolumn{4}{|c|}{$\begin{array}{c}\mathrm{TP}=33 \mathrm{FN}=1 \mathrm{FP}=6 \mathrm{TN}=0 \\
\text { Akurasi }=(\mathrm{TP}+\mathrm{TN}) / \mathrm{TP}+\mathrm{FP}+\mathrm{FN}+\mathrm{TN} \\
=(33+0) /(33+1+6+0) \\
=0,825 \\
=82,5 \%\end{array}$} \\
\hline
\end{tabular}

Beberapa catatan penting pada lokasi uji akurasi yaitu pada lokasi 5 yang diidentifikasi sebagai bangunan, ternyata kondisi aktual berupa ruang terbuka biru, selanjutnya lokasi 6 yang diidentifikasi sebagai bangunan ternyata merupakan kawasan terbuka hijau budidaya. Selanjutnya nomor 14 adalah area Monas (Monumen Nasional) yang mana pada model diidentifikasi sebagai bangunan namun kondisi aktual masih hijau. Hal serupa juga terjadi pada lokasi nomor 23, 25 dan 32 yang mana prediksi menyatakan bahwa di lokasi sampel terdapat bangunan tidak selaras RTRW namun ternyata masih hijau. Selanjutnya pada lokasi 26, pada prediksi dinyatakan bahwa di lokasi tersebut tidak ada bangunan not com- ply, namun ternyata di kondisi aktual terdapat bangunan di lokasi tersebut. Sementara itu, pada wilayah sampel lainnya, prediksi sudah sesuai dengan aktual. Catatan pada lokasi 34, 38 dan 40 pembangunan fisik di kawasan yang berdasarkan RTRW merupakan kawasan peruntukan khusus tanpa bangunan, terjadi dengan masif dan cakupannya luas.

Dari hasil uji akurasi dapat diketahui nilai akurasi model prediksi sebesar 82,5\% yang artinya adalah bahwa model prediksi bangunan tidak selaras dengan RTRW dalam penelitian ini memiliki tingkat kepercayaan cukup tinggi terhadap kondisi aktual. Hal ini juga dapat menjadi wujud pemantauan dan perhatian terhadap lokasi keberadaan 
bangunan tidak selaras dengan RTRW agar tidak terjadi ekspansi pembangunan fisik yang lebih parah serta menindaklanjuti bangunan yang tidak selaras dengan RTRW dengan solusi terbaik yang dapat disepakati para stakeholder.

\section{KESIMPULAN}

Berdasarkan penelitian yang dilakukan pada wilayah Provinsi DKI Jakarta dapat disimpulkan bahwa integrasi teknik penginderaan jauh dan analisis SIG dapat digunakan untuk mencapai tujuan dalam penelitian ini bagaimana kesesuaian pembangunan fisik perkotaan terhadap RTRW Provinsi DKI Jakarta, apakah mengikuti arahan sesuai dengan kawasan peruntukannya, sehingga diketahui dimana bangunan yang tidak mengikuti arahan dalam RTRW untuk dijadikan kawasan peruntukan khusus yang secara regulasi tidak boleh dibuat bangunan di atasnya.

Adapun total luasan bangunan yang tidak selaras dengan RTRW yaitu 1.016,08 hektar. Dari penelitian dapat diketahui bahwa kawasan dengan fungsi peruntukan terbuka hijau budidaya merupakan kawasan yang paling banyak memiliki bangunan tidak selaras dengan RTRW. Hasil uji akurasi menunjukkan bahwa tingkat akurasi model yaitu 82,5 \% yang artinya memiliki tingkat kepercayaan dan reliabilitas cukup tinggi. Dengan demikian hal ini dapat menjadi masukan bagi pemangku kepentingan untuk mengendalikan pembangunan fisik wilayah di area untuk fungsi kawasan khusus yang tidak dapat dibuat bangunan di atasnya dan mencari solusi untuk bangunan yang sudah terlanjur didirikan di wilayah tersebut.

\section{UCAPAN TERIMA KASIH}

Diucapkan terima kasih kepada Lembaga Pengelola Dana Pendidikan (LPDP) Kementerian Keuangan Republik Indonesia atas dukungan yang diberikan dalam mengerjakan penelitian ini.

\section{KONTRIBUSI PENULIS}

Penulis Pertama mendesain metode penelitian, analisis data, dan membuat naskah publikasi.

\section{DAFTAR PUSTAKA}

Abhishek, N., Jenamani, M., \& Mahanty, B. (2017). Urban growth in Indian cities: Are the driving forces really changing? Habitat International, 69, 48-57. https://doi.org/10.1016/ j.habitatint.2017.08.002

Ahmed, Z., Asghar, M. M., Malik, M. N., \& Nawaz, K. (2020). Moving towards a sustainable environment: The dynamic linkage between natural resources, human capital, urbanization, economic growth, and ecological footprint in China. Resources Policy, 67(April), 101677. https://doi.org/10.1016/ j.resourpol.2020.101677

Ardiansyah, Hernina, R., Suseno, W., Zulkarnain, F., Yanidar, R., \& Rokhmatuloh, R. (2019). Percent of building density (PBD) of urban environment: A multi-index Approach Based Study in DKI Jakarta Province. Indonesian Journal of Geography, 50(2), 154-161. https://doi.org/10.22146/ijg.36113

Arifin, H. S. (2014). Revitalisasi Ruang Terbuka Biru Sebagai Upaya Manajemen Lanskap Pada Skala Bio-Regional. Risalah Kebijakan Pertanian Dan Lingkungan, 1(3), 172-180. https:// doi.org/10.20957/jkebijakan.vli3.10294

As-syakur, A. R., \& Adnyana, I. W. S. (2009). Analisis indeks vegetasi menggunakan citra ALOS/AVNIR-2 dan Sistem Informasi Geografi (SIG) untuk evaluasi tata ruang Kota Denpasar. Jurnal Bumi Lestari, 9(1), 1-11. http:// www.academia.edu/download/31449981/45084379-01-Analisis-
Indeks-Vegetasi-Menggunakan-Citra-Alos.pdf

Christiawan, P. I. (2019). Tipe Urban Sprawl dan Eksistensi Pertanian di Wilayah Pinggiran Kota Denpasar. Jurnal Wilayah Dan Lingkungan, 7(2), 79-89. https://doi.org/10.14710/ jwl.7.2.79-89

Fahmi, F., Sitorus, S. R. P., \& Fauzi, A. (2016). Evaluasi Pemanfaatan Penggunaan Lahan Berbasis Rencana Pola Ruang Kota Baubau, Provinsi Sulawesi Tenggara. Tataloka, 18(1), 2739. http://ejournal2.undip.ac.id/index.php/tataloka

Fei, W., \& Zhao, S. (2019). Urban land expansion in China's six megacities from 1978 to 2015. Science of the Total Environment, 664, 60-71. https://doi.org/10.1016/ j.scitotenv.2019.02.008

Hidayati, I. N., Suharyadi, R., \& Danoedoro, P. (2018). Developing an Extraction Method of Urban Built-Up Area Based on Remote Sensing Imagery Transformation Index. Forum Geografi, 32(1), 96-108. https://doi.org/10.23917/ forgeo.v32i1.5907

Hou, H., Estoque, R. C., \& Murayama, Y. (2016). Spatiotemporal analysis of urban growth in three African capital cities: A gridcell-based analysis using remote sensing data. Journal of African Earth Sciences, 381-391. https://doi.org/10.1016/ j.jafrearsci.2016.08.014

Ilhami, F., Nugroho, D., \& Rocchadi, B. (2014). Pemetaan tingkat kerawanan rob untuk evaluasi tata ruang pemukiman daerah pesisir Kabupaten Pekalongan Jawa Tengah. Journal of Marine Research, 3(4), 508-515.

Kusuma, A. C., Irwani, \& Widada, S. (2013). Identifikasi Daerah Rawan Rob untuk Evaluasi Tata Ruang Pemukiman Di Kabupaten Demak. Journal of Marine Research, 2(3), 1-5. https://doi.org/10.14710/jmr.v2i3.3125

Lu, L., Guo, H., Corbane, C., \& Li, Q. (2019). Urban sprawl in provincial capital cities in China: evidence from multi-temporal urban land products using Landsat data. Science Bulletin, 64 (14), 955-957. https://doi.org/10.1016/j.scib.2019.04.036

Mukhoriyah, Sari, N. M., Sharika, M., \& Hanifati, L. N. (2019). Identifikasi Ketersediaan Ruang Terbuka Hijau Kecamatan Kramat Jati Kodya Jakarta Timur Menggunakan Citra Pleiades. Jurnal Planologi, 16(2), 158-168.

Pemerintah Provinsi DKI Jakarta. (2012). Peraturan Daerah Provinsi DKI Jakarta Nomor 1 Tahun 2012 tentang Rencana Tata Ruang Wilayah Jakarta 2030.

Prasetyo, A., Koestoer, R. H., \& Waryono, T. (2017). Pola Spasial Penjalaran Perkotaan Bodetabek: Studi Aplikasi Model Shannon'S Entropy. Jurnal Geografi Gea, 16(2), 144. https:// doi.org/10.17509/gea.v16i2.2439

Purbawiyatna, A., Kartodihardjo, H., Alikodra, H. S., \& Prasetyo, L. B. (2012). Analisis Kebijakan Pengelolaan Hutan Rakyat untuk Mendorong Fungsi Lindung. Jurnal Pengelolaan Sumber Daya Alam Dan Lingkungan, 2(1), 1-10.

Putra, D. B., Suprayogi, A., \& Sudarsono, B. (2019). Analisis Kerawanan Banjir pada Kawasan Terbangun Berdasarkan Klasifikasi Indeks EBBI (Enhanced Built-Up and Bareness Index) Menggunakan SIG (Studi Kasus Di Kabupaten Demak). Jurnal Geodesi Undip, 8(1), 93-102.

Sari, N. M., \& Kushardono, D. (2016). Quality analysis of single tree object with OBIA and Vegetation Index. Geoplanning: Journal of Geomatics and Planning, 3(2), 93-106. https:// doi.org/10.14710/geoplanning.3.2.93-106

Sari, N. M., \& Kushardono, D. (2019). Analisis dampak pembangunan infrastruktur Bandara Internasional Jawa Barat terhadap alih fungsi lahan pertanian melalui citra satelit resolusi tinggi. Jurnal Geografi, 11(2), 146-162. https:// doi.org/10.24114/jg.v11i2.13470Suryanta, J., \& Nahib, I. (2016). Kajian Spasial Evaluasi Rencana Tata Ruang Berbasis Kebencanaan Di Kabupaten Kudus Provinsi Jawa Tengah. Majalah Ilmiah Globe, 18(1), 33. https://doi.org/10.24895/ mig.2016.18-1.392

Wu, K. Y., \& Zhang, H. (2012). Land use dynamics, built-up land expansion patterns, and driving forces analysis of the fast- 
growing Hangzhou metropolitan area, eastern China (1978-

2008). Applied Geography, 34, 137-145. https:// doi.org/10.1016/j.apgeog.2011.11.006

Yang, J., Wu, T., \& Gong, P. (2017). Implementation of China's new urbanization strategy requires new thinking. Science Bulletin, 62 (2), 81-82. https://doi.org/10.1016/j.scib.2016.12.013 